\title{
Science Over Stigma: Lessons and Future Direction of HIV-to-HIV Transplantation
}

\author{
Samantha B. Klitenic ${ }^{1}$ Macey L. Levan ${ }^{1} \cdot$ Sarah E. Van Pilsum Rasmussen ${ }^{1} \cdot$ Christine M. Durand $^{2,3}$
}

Accepted: 6 September 2021 / Published online: 18 November 2021

(c) The Author(s), under exclusive licence to Springer Nature Switzerland AG 2021

\begin{abstract}
Purpose of Review The HIV Organ Policy Equity (HOPE) Act permits transplantation from donors-with-HIV to recipientswith-HIV (HIV D $/ \mathrm{R}+$ ). We assess HOPE implementation, summarizing progress and challenges at clinical, legislative, and community levels.

Recent Findings As of July 2021, there have been 300 kidney and 87 liver transplants within HOPE research studies in the USA. Early HIV D +/R + kidney transplant outcomes show excellent patient survival (100\%) and graft survival (92\%). The number of HOPE donors continues to grow annually but remains lower than projections. State-level policy restrictions are identified in 34 states; however, these do not seem to have impacted practice; 16 states have passed new legislation to facilitate HIV D + / R + transplantation. Stigma related to HIV and low donor registration rates pose additional barriers.

Summary Early outcomes of HOPE Act transplants are encouraging. Progress to reach full implementation and realize the full benefit of this innovation is ongoing.
\end{abstract}

Keywords HIV $\cdot$ HIV-positive donor $\cdot$ HIV Organ Policy Equity Act $\cdot$ HIV transplantation

\section{Introduction}

As of 2021, approximately 37.6 million individuals globally, and 1.2 million in the USA, are living with HIV infection [1, 2]. HIV is associated with increased risk of end-stage organ disease such as end-stage renal disease (ESRD) and end-stage liver disease (ESLD), both of which may require transplantation. Over the past two decades, solid organ transplantation (SOT) has become the treatment of choice for organ failure in persons living with HIV (PLWH), since mortality on

This article is part of the Topical Collection on OPTN Policy

Christine M. Durand

christinedurand@jhmi.edu

1 Department of Surgery, Johns Hopkins University School of Medicine, Baltimore, MD, USA

2 Department of Medicine and Oncology, Johns Hopkins University School of Medicine, 725 North Wolfe Street/PCTB 228, Baltimore, MD 21205, USA

3 Sidney Kimmel Cancer Center, Johns Hopkins University School of Medicine, 725 North Wolfe Street, Baltimore, MD 21205, USA dialysis is higher, and pretransplant survival is shorter, for PLWH than for individuals without HIV [3-5]. As a result, the number of kidney and liver transplants performed in this population has steadily increased [6]. Still, PLWH in need of a kidney transplant experience an increased risk of waitlist mortality and decreased access to transplantation when compared to candidates without HIV [7•]. Kidney transplantation reduces this mortality by $79 \%$ [8]. Liver transplantation has also been shown to provide a survival benefit for those with decompensated liver disease and HIV [9]. Utilizing organs from PLWH might lessen this mortality further by increasing access to transplantation.

The practice of kidney transplantation using donors from PLWH was first pioneered in South Africa with excellent early outcomes [10]. This experience, as well as major advances in HIV medicine and transplantation, inspired the HIV Organ Policy Equity (HOPE) Act. The HOPE Act was signed into law in 2013, reversing the decades-long federal ban on the use of organs from donors with HIV, and calling for research criteria to study transplantation from donors with HIV to recipients with HIV (HIV $\mathrm{D}+/ \mathrm{R}+$ ). This milestone represented the culmination of physicians', national transplant and AIDS advocacy 
groups', US policymakers', and healthcare officials' joint efforts to improve access to transplants for vulnerable populations, expand the national donor pool, and address the organ shortage. Thereafter, three actions were taken to fulfill HOPE Act requirements-(1) in June 2015, the Department of Health and Human Services (HHS) revised the federal ban on recovery of organs from HIV D + to allow transplantation within research protocols [11], (2) in November 2015, the Organ Procurement and Transplantation Network (OPTN) revised policies to permit the recovery of organs from donors with HIV pursuant to the criteria developed by the Secretary, and (3) in November 2015, the Secretary published research criteria relating to HIV D + / R + transplantation [12].

In this review, we discuss current implementation of the HOPE Act, summarize progress to date and remaining barriers including state-level regulations and community perceptions, and offer recommendations for the future.

\section{Clinical Progress in HOPE Implementation}

As of November 2017, 22 transplant centers in 15 states (10 of the 11 UNOS regions) had been approved to perform HIV-to-HIV transplants [13, 14]. Region 6, which comprises six states in the Pacific Northwest, was the only UNOS region without any HOPE-approved transplant centers [14, 15]. As of July 2021, 35 transplant centers in 21 states had been approved to perform HIV-to-HIV transplants; 19 of these centers are clustered in the eastern United States, and Region 6 still does not have any HOPE-approved transplant centers (Fig. 1) [16]. Thirty-three of these transplant centers have partnered to form the HOPE in Action Multicenter consortium, a collaborative performing multicenter studies (NCT02602262, NCT03500315, NCT03734393) to study outcomes of HOPE Act transplants.

There has also been increased engagement of Organ Procurement Organizations (OPOs) to evaluate HOPE donors. In 2017, only 16 out of 58 OPOs had evaluated a HOPE
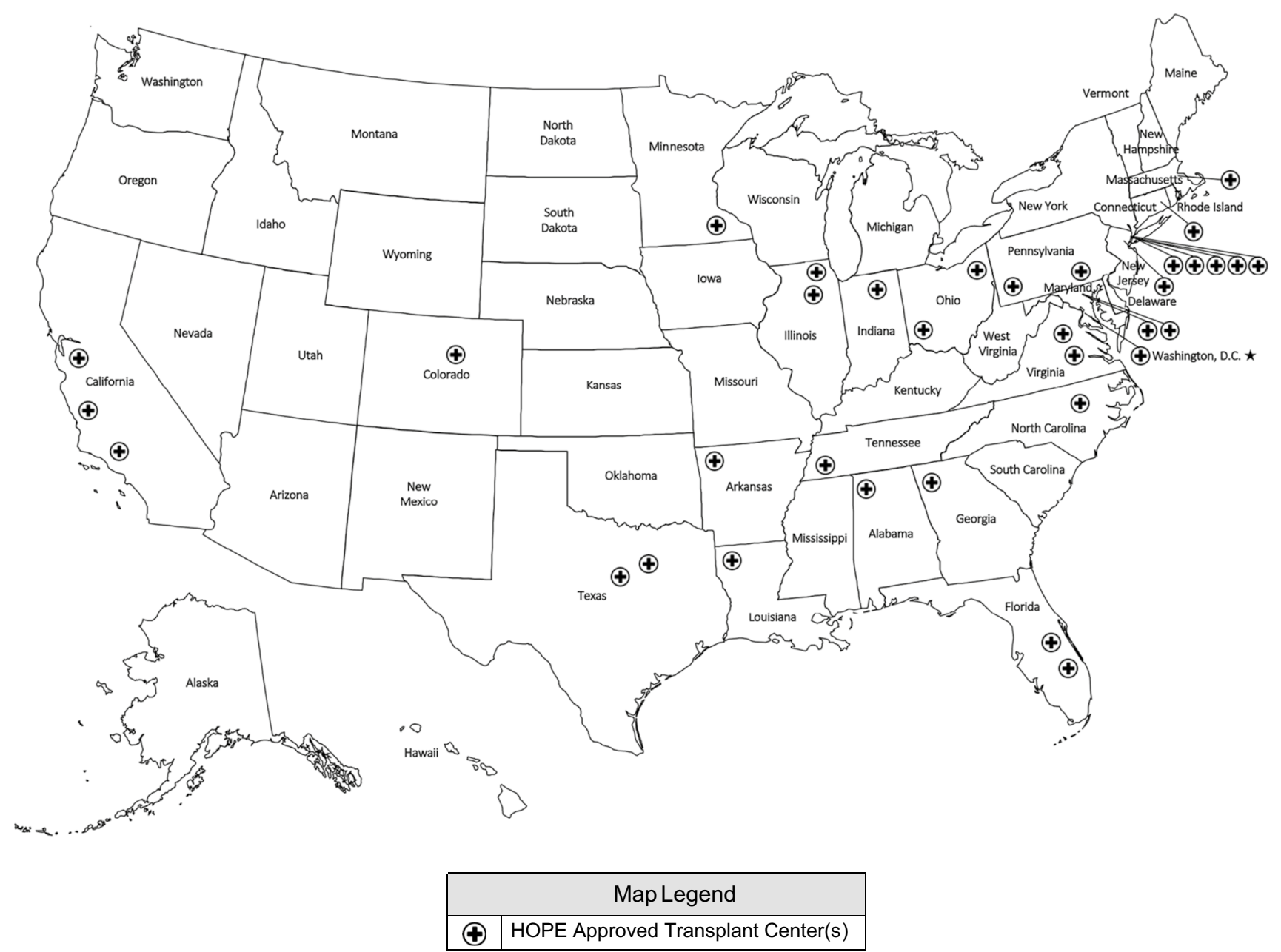

Fig. 12021 HOPE implementation 
donor [14]. As of July 2021, 46 of 58 OPOs have evaluated HOPE donors. Together, efforts of transplant centers and OPOs have led to a total of 300 kidney and 87 liver transplants within the HOPE in Action studies as of July 2021. The breakdown of transplants by organ (liver, kidney, simultaneous liver-kidney) and donor type (positive, false-positive, negative) are shown in Table 1. As of July 2021, there have been 144 true positive or false positive HOPE donors. Only kidney and liver transplants have been performed to date, as of October 2018. Heart and lung transplants are also approved [17] and anticipated in the future.

\section{Clinical Risks Affecting Implementation of the HOPE Act}

Several biologic issues specific to transplant recipients with HIV have been raised with respect to HIV D + $/ \mathrm{R}+$ transplantation. First, HIV superinfection, which occurs when a PWLH is infected with a second, distinct strain of HIV, has been considered a primary theoretical risk of HIV-to-HIV transplantation [18]. The concern has been that if a donor is infected with drug-resistant HIV, this could lead to HIV breakthrough in the transplant recipient if their antiretroviral therapy (ART) is not active against the donor's HIV strain [19]. Interestingly, a 2018 survey, designed to assess knowledge and attitudes surrounding HIV-to-HIV transplantation at US transplant centers, revealed that a majority (72.5\%) of respondents perceived the risk of HIV superinfection to be clinically manageable $[7 \bullet]$.

Table 1 General Overview of HOPE Implementation to Date

\begin{tabular}{ll}
\hline & March 2016-July 2021 \\
\hline HOPE approved transplant centers & 35 \\
OPOS that have evaluated HOPE donors & 46 \\
HOPE donors & 144 \\
Transplants within HOPE studies & Kidney only, 286 \\
& True positive, 128 \\
& False positive, 63 \\
& Negative, 95 \\
& Liver only, 73 \\
& True positive, 39 \\
& False positive, 13 \\
& Negative, 21 \\
& Simultaneous Liver \\
Kidney (SLK)*, 14 \\
True positive, 7 \\
False positive, 3 \\
Negative, 4
\end{tabular}

\footnotetext{
*Each SLK is counted as 2 organ transplants
}

Second, there have been concerns that the risk of organ rejection could be increased with use of an organ from a donor with HIV. Compared to recipients without HIV, several studies have found higher rates of organ rejection than expected in both kidney [20,21] and liver transplantation [22, 23].

Finally, another theoretical risk of HIV-to-HIV kidney transplantation that has been raised is the possibility of HIVrelated organ disease in the allograft. In a study by Canaud et al., which included 19 HIV D - / R + kidney transplants, HIV infection of podocytes was observed in 5 recipients despite the fact that plasma HIV RNA was undetectable. This small group of patients experienced nephrotic-range proteinuria, progressive focal segmental glomerulosclerosis, and subsequent renal dysfunction, raising caution [24]. Some surmised that this phenomenon might occur particularly if kidneys from donors with HIV were utilized. Similarly, since HIV has been identified as a risk factor for nonalcoholic fatty liver disease and non-alcoholic steatohepatitis [25], concerns about higher rates of fibrosis or steatosis in liver allografts from donors with HIV has also been raised as a concern.

\section{First Outcomes of HIV D + /R + Kidney Transplantation}

In the USA, the first prospective multicenter pilot study of HIV-positive deceased donor to HIV-positive recipient kidney transplantation was recently published. Conducted between March 2016 and July 2019, this pilot study including 75 kidney transplant recipients with HIV, comparing outcomes between HIV D $+/ \mathrm{R}+$ and HIV $\mathrm{D}-/ \mathrm{R}+$. This study demonstrated that overall transplant and HIV outcomes were excellent [26•]. There were no deaths or differences in 1-year graft survival $(91 \% \mathrm{D}+\mathrm{vs.} .92 \% \mathrm{D}-)$, 1-year mean estimated glomerular filtration rate $(63 \mathrm{~mL} / \mathrm{min}$ $\mathrm{D}+$ vs. $57 \mathrm{~mL} / \mathrm{min} \mathrm{D}-$ ), HIV breakthrough (4\% D + vs. $6 \%$ D-), infectious hospitalizations ( $28 \%$ vs. $26 \%$ ), or opportunistic infections [26•].

With regard to HIV superinfection, HIV breakthrough was quite rare. In a related study from the HOPE in Action group, virologists performed in depth phylogenetic analyses of donor and recipient virus and found no evidence of HIV superinfection in recipients [27]. Similarly, in a long-term study of HIV D + / R + kidney transplant recipients in South Africa, superinfection was not identified [28]. These results suggest that loss of HIV suppression, as a result of donorderived HIV superinfection, is not a major clinical concern in carefully monitored recipients with HIV on ART.

Also reassuring, in this first HOPE in Action HIV $\mathrm{D}+/ \mathrm{R}+$ kidney transplantation study, there was no evidence of HIV-related kidney disease in the allograft, as had been 
observed in the Canaud study. Furthermore, HIV-related kidney disease was not reported in earlier studies of HIV $\mathrm{D}-/ \mathrm{R}+$ transplantation in the USA [20] or in South African studies of HIV D+/R + transplantation [29]. Long-term graft function will need to be monitored within the HOPE in Action study to further assess this risk.

Rejection may be a remaining challenge for HIV $\mathrm{D}+/ \mathrm{R}+$ kidney transplantation. In the HOPE in Action pilot, 1 -year rejection rates were higher for $\mathrm{D}+$ recipients than for D- recipient (50\% vs. $29 \%$ ) [26•]. Overall, the proportion of recipients with rejection was lower $(21 \%)$ in those who received antithymocyte globulin (ATG) for induction [26•]. This observation aligns with other studies of HIV D $-/ \mathrm{R}+$ kidney transplantation, which have suggested that lymphocyte depleting regimens may be protective in this population $[30,31]$.

The published experience of HIV D +/R + liver transplantation remains small and includes 3 successful international case reports with limited follow-up [32-34]. More data are needed and published studies from the HOPE in Action Multicenter Consortium are anticipated in the near future.

The coronavirus disease 2019 (COVID-19) outbreak posed a new threat to transplant recipients with HIV. The Centers for Disease Control (CDC) has classified both SOT recipients and PLWH as high-risk populations, more likely to develop severe case of COVID-19 [35, 36••]. The first report of COVID-19 in the HOPE in Action Consortium noted a high mortality in kidney and liver transplant recipients with HIV [36••]. Between March 20, 2020, and September 25, 2020, there were 11 cases of COVID-19 among the 291 kidney and liver transplant recipients within the HOPE in Action Multicenter Consortium [36••]. Ninety-one percent of these cases resulted in hospitalization and 36\% resulted in death [36••]. Larger studies in this population are needed to determine whether this increased risk holds up over time.

There remains further ground to cover to realize the projected potential of HOPE implementation. Though there have been 144 HOPE donors to date, prior studies from Boyarksy and Richterman projected up to 300-500 potential HOPE donors each year [37, 38]. In the first 2 years of HOPE implementation, organs were recovered from only 56 HOPE donors [39]. In the next section, we review the remaining challenges, specifically the nascency of HIV-to-HIV transplantation, legal barriers, and community and societal perceptions, and provide suggestions for moving forward.

\section{Current Challenges}

\section{Nascency of HIV-to-HIV Transplantation}

The field of transplantation is constantly evolving with new technology, procedures, and regulatory changes.
However, the newest scientific advancements and clinical innovations are often slow to gain acceptance and disseminate. This process has been described as the diffusion of innovation theory and can apply to new health care practices [40]. In the case of HIV D $+/ R+$ transplantation, we are likely still in the early adoption phase. As more HIV D + $/ \mathrm{R}+$ transplants are performed and reported in the medical literature and public arena over time, we anticipate to see further expansion of this transplant innovation to a larger majority.

\section{Legal Barriers to HOPE Act Implementation}

The passage of the HOPE Act represented a long-overdue movement to align outdated HIV law and policy with scientific evidence and advancements in ART that substantially improved the life expectancy of PLWH. However, even after changes to federal policy, certain state-level regulations remain that could potentially restrict HIV-to-HIV transplantation [13]. Each state's organ and tissue donation laws for PLWH (Table 2) fall into one of the following categories(1) laws that allow the use of organs and tissue from PLWH through an explicit HOPE Act exception, (2) laws that allow the use of organs and tissue from PLWH for transplant and/ or research only under certain circumstances, (3) laws that prohibit organ donation from PLWH in all circumstances, and (4) laws that are silent regarding organ and tissue donation from PLWH.

Five states allow the use of organ and tissue donations from PLWH for transplant and research through an explicit HOPE Act exception and eleven states allow the use of organ and tissue donations from PLWH, under certain circumstances (Table 2). These eleven states contain laws that generally prohibit PLWH from donating organs and tissue for transplantation or research but for the following exceptions-(1) a research and informed consent exception, (2) a research and informed consent exception provided the transplant is necessary to save a life, (3) a research and informed consent provided the organ or tissue's HIV infected status is disclosed on the consent form, (4) an exception that allows an organ to be transplanted without the donor first being tested for HIV (because of exigent circumstances) provided the recipient gives informed consent, (5) a research exception only, and (6) an informed consent exception only.

These research and consent exceptions are often ambiguous. For example, in states where a research exception applies, the relevant terms (i.e. "medical research" or "research purposes") are rarely defined. Other states, such as Florida and Kentucky, apply an exception where the transplant "is necessary to save a life," but this is not defined. However, 6 of these 11 states have been participating in HOPE Act studies, indicating that in practice this has not been an issue. 


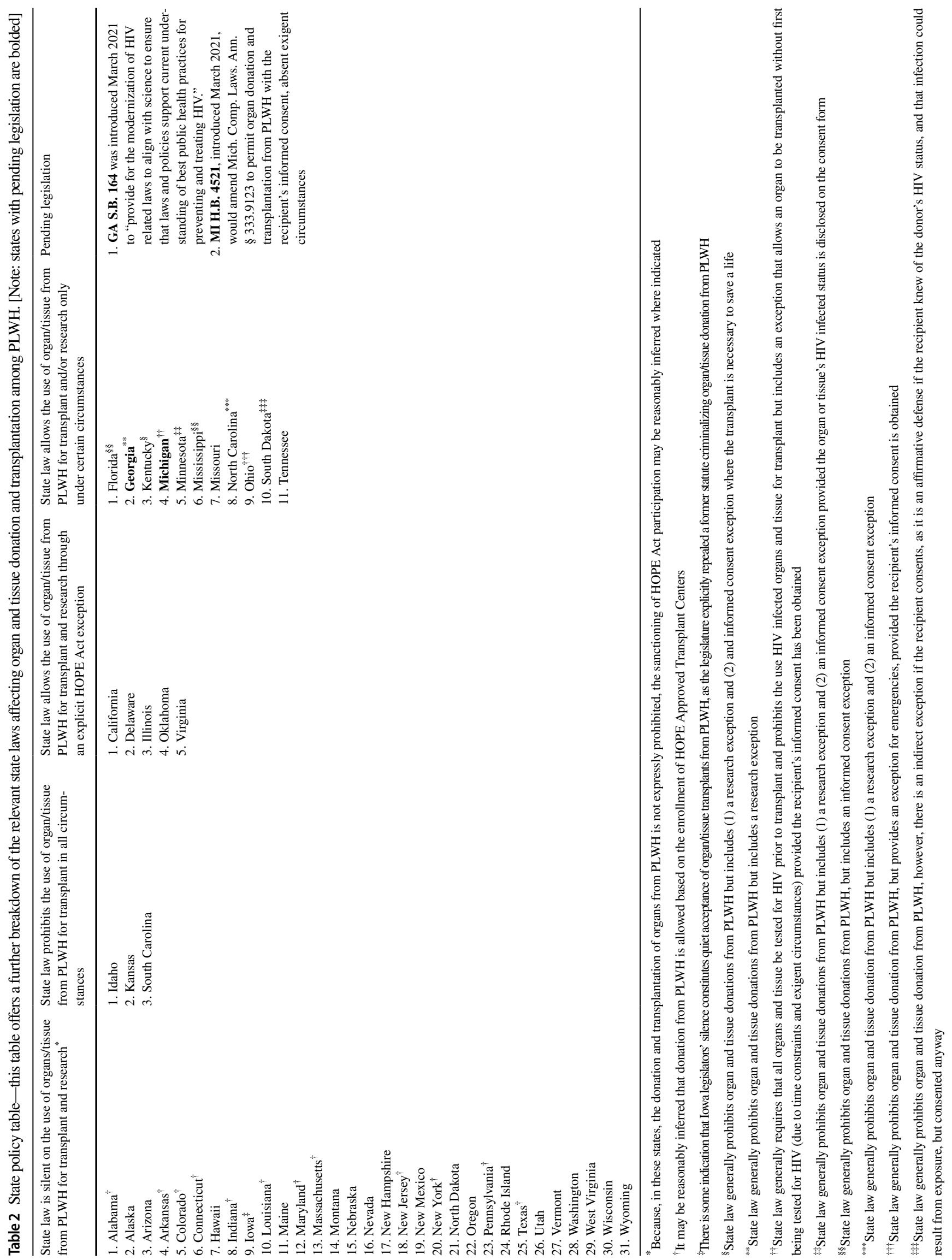


Another remaining question is how the legal status of transplantation from donors with HIV would change if and when HIV D + $/ \mathrm{R}+$ transplantation moves outside of research protocols into clinical practice. The HOPE Act contains a mandate that requires the HHS to review outcomes to determine whether HIV D+/R + transplants may continue, within or outside of research [12]. This change, if it occurs, could theoretically affect states such as Georgia and Missouri that only allow HIV D +/R + under research exception only.

Only three states, Idaho [41], Kansas [42], and South Carolina [43] explicitly prohibit organ and tissue donations from PLWH under all circumstances (Table 2). In these states, it is a felony for PLWH who know their HIV status to donate organs for transplantation. Despite these laws, a case search of the legal databases WestLaw, LexisNexis, and HeinOnline yielded no cases to date in which PLWH were prosecuted for donating organs for transplantation [13]. Furthermore, with these statutes, it is unclear which parties would be liable for an illegal HIV D $+/ R+$ transplant, since there is not specific reference to transplant professionals, donors, or decedents. As such, it seems unlikely that these prohibitions would be used to prosecute in the future.

The remaining 31 states (Table 2) are silent and do not explicitly address the possibility that organs and tissues from PLWH can be used for transplantation. Thus, members of the PLWH community, transplant physicians, transplant centers, and OPOs are left to determine how to move forward with research in these states. Of note, however, is the fact that there seems to be a high level of HOPE approved transplant center and OPO participation in these states. Twelve of the thirty-one silent states have a HOPE approved transplant center(s). Additionally, in a 2018 survey of 58 OPOs, all
55 responding OPOs reported support for the HOPE Act and research related to HIV D $+/ \mathrm{R}+$ transplantation [44]. In our opinion, the high level of OPO and transplant center participation in these states lead us to conclude that the permissibility of HOPE Act participation may be reasonably inferred (Table 3 ).

\section{Social Barriers Affecting Implementation of the HOPE Act}

\section{Stigma, Attitudes, and Beliefs}

HIV-related stigma has existed since 1980s, when the epidemic was officially reported in the USA and been documented extensively since. In 1981, the New York Times published an article entitled "Rare Cancer Seen in 41 Homosexuals" and at this point, the term "gay cancer" entered the US vernacular [45]. Several years later, in 1988, Congress amended the National Organ Transplant Act (NOTA), criminalizing the use of organs from donors "infected with the etiologic agent for AIDS" [46]. Between 1987 and 1997, only 32 kidney transplants were performed among PLWH in the USA with low rates of patient and graft survival [47]. Additionally, a 1997 survey of 248 renal transplant centers in the USA revealed that a majority of the 148 responding providers would not refer PLWH for kidney transplantation [48]. In 2003, a survey of transplant surgeons demonstrated that, even with effective ART, still only $33 \%$ supported SOT among PLWH [49].

Although SOT is now considered the standard of care for PLWH and ESRD, several recent studies have shown that

Table 3 Table of HOPE Act approved transplant centers in states where law is silent

\begin{tabular}{ll}
\hline $\begin{array}{l}\text { States where the law is silent on the use of } \\
\text { organs/tissue from PLWH for transplant and } \\
\text { research }\end{array}$ & $\begin{array}{l}\text { Permissibility of HOPE Act participation may be reasonably inferred from the enrollment of } \\
\text { HOPE Act approved transplant center(s) }\end{array}$ \\
\hline Alabama & University of Alabama Hospital \\
Arkansas & University of Arkansas Medical Sciences Hospital \\
Colorado & University of Colorado Hospital/Health Science \\
Connecticut & Yale New Haven Hospital \\
Indiana & Indiana University Health \\
Louisiana & Ochsner Foundation Hospital \\
Maryland & (1) Johns Hopkins Hospital and (2) University of Maryland Medical System \\
Massachusetts & Massachusetts General Hospital \\
New Jersey & Saint Barnabas Medical Center \\
New York & (1) Montefiore Medical Center, (2) Mount Sinai Medical Center, (3) New York-Presbyterian/ \\
Pennsylvania & Columbia, (4) New York-Presbyterian/Weill Cornell and (5) NYU Medical Center \\
& (1) University of Pittsburgh Medical Center and (2) The Hospital of the University of Penn- \\
Texas & sylvania \\
& (1) Methodist Dallas Medical Center and (2) UT Southwestern Medical Center/William P. \\
& Clements Jr. University Hospital
\end{tabular}


PLWH are less likely to be successfully referred and listed for kidney transplant with psychosocial factors and systemic barriers likely playing a role [50,51].

Deceased donor evaluation may also be impaired by stigma and community perceptions. In a study investigating HOPE Act barriers experienced by OPOs, 20 OPO

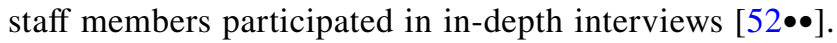
The interviews revealed high levels of knowledge about the HOPE Act, with many respondents having evaluated referrals of HIV-positive donors and approached families

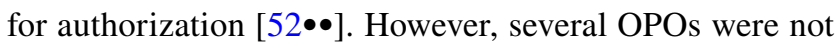
evaluating known HIV-positive cases, and although HIVpositive status was not an official rule-out, some OPO staff members reported looking for ways to rule out HIV-positive

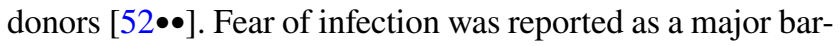
rier, and some interviewees described stigmatizing beliefs about HIV in interactions with OPO and hospital staff, such as assuming HIV was a fatal disease or that PLWH were more likely to be homeless or have disrupted families [52••].

Despite modern advances in HIV treatment and management and continued global action to reduce HIV-related stigma, HIV-related stigma persists today, even in countries that have superior HIV management and prevention programs as well as an outspoken and dedicated activist community [46]. In a recent interview study of recipient experiences with HIV D $+/ \mathrm{R}+$ transplantation, participants reported concerns about stigma both within the healthcare system and in society at large [53]. Some participants believed that transplant candidates living with HIV were treated differently than transplant candidates not living with $\mathrm{HIV}$, and others were concerned about the increased risk of HIV status disclosure during the transplant process [53]. Thus, stigmatizing attitudes and beliefs surrounding PLWH and HIV D + / R + transplantation could restrict HOPE Act implementation by impacting PLWH's willingness to donate organs, PLWH's willingness to accept organs from other PLWH, provider's willingness to refer PLWH for transplant, etc. Ultimately, one of the greatest barriers to using donated organs from PLWH may be societal [54]. Despite this, the interviews with recipients of HIV D + / + transplants also found that some participants believed that HIV $\mathrm{D}+/ \mathrm{R}+$ transplantation could help combat stigma against PLWH, particularly by allowing PLWH to register as organ donors [53]. As HIV D +/R + transplantation expands, great care should be paid to patient's concerns regarding privacy and stigma, while recognizing that HIV D+/R + transplantation may be an opportunity to reverse social stigma against PLWH.

\section{Educational Barriers}

Successful implementation of HIV D $+/ R+$ transplantation under the HOPE Act requires awareness and support from OPOs, transplant centers, and the PLWH community. Renewed educational efforts are necessary to better inform OPOs, transplant centers, and members of the PLWH community of the legality of HIV D+/R + transplantation under the HOPE Act, the HOPE Safeguards and Research Criteria, and the outcomes of HIV D $+/ \mathrm{R}+$ transplants.

The first survey of PLWH conducted in the USA following the HOPE Act showed a high willingness to donate (79.8\%) but a lack of knowledge regarding the HOPE Act (24.6\%) among the PLWH community (79.8\%) [52••, 55]. Rasmussen et al.'s 2018 survey of 104 transplant center surgeons, physicians, nurses, pharmacists, and administrators demonstrated that $21.4 \%$ of transplant center staff were unaware of the research protocols (pursuant to HHS criteria) required to perform HIV-to-HIV transplantation under the HOPE Act [7•]. 56.2\% of respondent transplant center staff reported no plans to perform HIV D $+/ R+$ transplants. Unsurprisingly, centers without plans to implement HIV $\mathrm{D}+/ \mathrm{R}+$ protocols were more likely to believe that PLWH would be unlikely to accept HIV + donor organs than centers with HIV D+/R + in place [7•].

Both of these studies underscore the need for communitylevel education to ensure that PLWH know that they may legally donate an organ and that the registration process is the same. Addressing these and any other educational barriers that may arise can help reduce HIV-related stigma, improve public perception and attitudes surrounding HIVto-HIV transplantation, and increase HOPE Act support and participation.

\section{Social Progress}

A 2018 survey of 114 US transplant centers regarding planned practice of HIV $\mathrm{D}+/ \mathrm{R}+$ transplantation showed promising results. Fifty transplant centers (43.8\%) reported that their centers were planning to perform HIV $\mathrm{D}+/ \mathrm{R}+$ transplants $[7 \bullet]$. Also, reassuring was the finding that of respondents, $104(91.2 \%)$ were aware that HIV $\mathrm{D}+/ \mathrm{R}+$ was legal. Of the centers planning HOPE protocols, overall knowledge of HIV D $+/ \mathrm{R}+$ transplants reported in peer-reviewed publications was high. Still, though many of the transplant center programs developing HOPE protocols reported plans to perform HIV D + /R + kidney $(98.0 \%)$ and liver $(68.0 \%)$ transplants, few centers reported plans to perform pancreas and heart transplants.

Still, other recent studies indicate high willingness among PLWH to accept HIV + organs [55]. One survey found that respondents from transplant centers that had already performed a HOPE transplant were more willing to accept HIV + deceased donor organs [55], suggesting that PLWH's willingness to accept HIV + organs will likely increase as more HIV D +/R + transplants are performed. 


\section{Recommendations for the Future}

Below are several recommendations to ensure successful and complete HOPE Act implementation (Box 1).

Box 1. Future recommendations to continue expanding the implementation of the HOPE Act on a national level

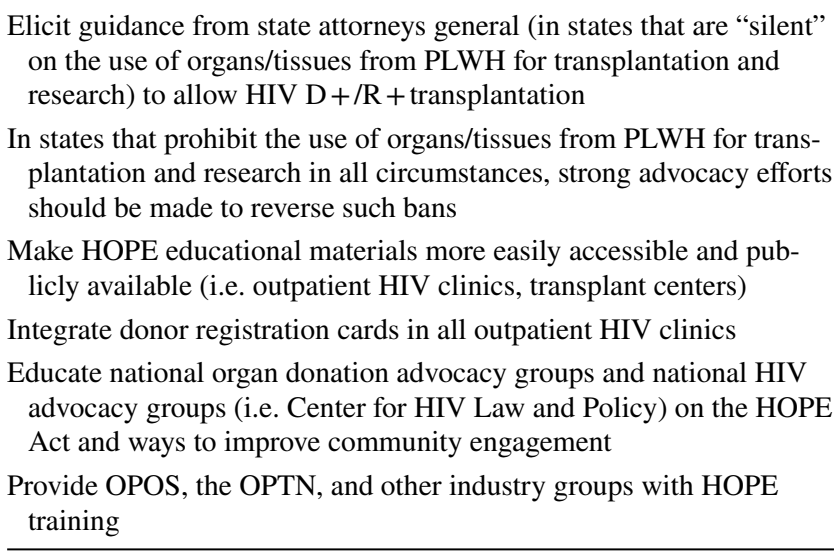

\section{Obtain Waivers by State Attorneys General and Increase Advocacy Efforts}

As described above, the vast majority of state legislatures remain silent on the use of organs and tissue from PLWH for transplantation. In these states, and possibly even in states that prohibit organ and tissue donation from PLWH in all circumstances without exception, it would be beneficial to elicit guidance from state attorneys general to endorse the use of organ and tissue donation within the context of HOPE Act research and address any foreseeable legal barriers to full, national HOPE implementation.

To elicit guidance from attorneys general, a letter should be drafted: (1) explaining the changed federal status of the law regarding HIV-infected organ and tissue donation (i.e. the HOPE Act); (2) describing the state legislature's failure to update state law to reflect the federal sanctioning of organ and tissue donation from PLWH within HOPE Act clinical research trials; (3) reviewing the current science surrounding HIV, outcomes of HIV-to-HIV-transplantation, and potential opportunities to increase the donor pool through HIV-to-HIV transplantation; and (4) requesting the state attorney general's interpretation of state law, particularly whether state law allows organ and tissue donation from PLWH within a HOPE Act context. Ideally, the state attorney general would respond with a clear interpretation of state law and/or guidance about whether the state legislature's silence is, in effect, permission to proceed with HOPE Act transplants.
In the three remaining states that completely prohibit the use of organs from donors with HIV, increased advocacy efforts should be implemented to reverse such bans.

\section{Increase Availability and Accessibility of HOPE Educational Materials and Training Tools}

Increasing the availability and accessibility of HOPE education materials would be extremely beneficial on the community-, OPO-, transplant center-, and advocacy group-levels. Targeted education efforts should ensure that members of the PLWH community are aware of the HOPE Act and how to register as a donor. Likewise, OPOs, transplant centers, and advocacy groups should be educated regarding HOPE protocols and should be trained and equipped with the skills necessary to work with vulnerable, stigmatized populations. OPOs especially play an essential role in realizing and communicating the full potential of the HOPE Act, as they are responsible for evaluating deceased donor referrals, making organ offers to transplant centers, and recovering organs [56].

\section{Integrate Donor Registration Cards in all Outpatient HIV Clinics}

A cross-sectional survey of 115 PLWH at a Johns Hopkins clinic revealed that while $80 \%$ were willing to be organ donors, only $22 \%$ were registered as such [57]. In 2018, Bhamidipati et al. observed a $34 \%$ increase in organ donor registration rates during a three-month period when donor registration cards were dispensed at outpatient HIV clinics [58]. Implementing this simple practice is one effective way of increasing HOPE Act awareness and donor registration rates among $\mathrm{PLWH}$, while bridging existing knowledge gaps.

\section{Conclusion}

The passage of the HOPE Act marked an important step toward increasing the donor pool and increasing PLWH's access to transplant. Though barriers remain, and progress is gradual, the field of HIV D+/R+transplantation is continuing grow and evolve. Clinical and scientific data from the ongoing HOPE studies will continue to inform future efforts to ensure successful and complete HOPE Act implementation.

Abbreviations Anti-IL2R: Interleukin-2 receptor blocker; ART: Antiretroviral therapy; ATG: Anti-thymocyte globulin; CKD: Chronic kidney disease; COVID-19: Coronavirus disease 2019; DOI: Diffusion of innovation; ESLD: End stage liver disease; ESOD: End stage organ disease; ESRD: End stage renal disease; HHS: Department of Health and Human Services; HIV + : HIV-infected; HIV D +/R + : HIVpositive donor to HIV-positive recipient; HIV D - /R + : HIV-negative donor to HIV-positive recipient; HOPE Act: HIV Organ Policy Equity 
Act; NOTA: National Organ Transplant Act; OPO: Organ procurement organization; OPTN: Organ Procurement and Transplantation Network; PLWH: Persons living with HIV; SOT: Solid organ transplantation; SRTR: Scientific Registry of Transplant Recipients

\section{References}

Papers of particular interest, published recently, have been highlighted as:

- Of importance

$\bullet$ Of major importance

1. Joint United Nations Programme on HIV/AIDS (UNAIDS). (2021). Global HIV \& AIDS statistics - 2021 fact sheet. Available at: https://www.unaids.org/en/resources/fact-sheet. Accessed 17 June, 2021.

2. Centers for Disease Control and Prevention. Estimated HIV incidence and prevalence in the United States, 2015-2019. HIV Surveillance Supplemental Report 2021;26(No. 1). http://www. cdc.gov/hiv/library/reports/hiv-surveillance.html. Published May 2021. Accessed 17 June, 2021.

3. Werbel WA, Durand CM. Solid Organ Transplantation in HIVinfected recipients: history, progress, and frontiers. Curr HIV/ AIDS Rep. 2019 Jun;16(3):191-203. https://doi.org/10.1007/ s11904-019-00440-x.

4. Bickel M, Marben W, Betz C, et al. End-stage renal disease and dialysis in HIV-positive patients: observations from a long-term cohort study with a follow-up of 22 years. HIV Med. 2013 Mar;14(3):12735. https://doi.org/10.1111/j.1468-1293.2012.01045.x.

5. Ragni MV, Eghtesad B, Schlesinger KW, Dvorchik I, Fung JJ. Pretransplant survival is shorter in HIV-positive than HIVnegative subjects with end-stage liver disease. Liver Transpl. 2005;11:1425-1430. https://doi.org/10.1002/lt.20534.

6. Shaffer AA, Durand CM. Solid organ transplantation for HIV-infected individuals. Curr Treat Options Infect Dis. 2018;10(1):107-20. https://doi.org/10.1007/s40506-018-0144-1.

7. Van Pilsum Rasmussen SE, Bowring MG, Shaffer AA, et al. Knowledge, attitudes, and planned practice of HIV-positive to HIV-positive transplantation in US transplant centers. Clin Transplant. 2018;32(10):e13365-e13365. https://doi.org/10. 1111/ctr.13365. (This study identifies several remaining transplant center-level barriers to HIV $D+/ R+$ transplantation, including geographic clustering of liver and kidney transplant programs and concerns regarding PLWH's willingness to accept HIV+ donor organs.)

8. Locke JE, Gustafson S, Mehta S, et al. Survival benefit of kidney transplantation in HIV-infected patients. Ann Surg. 2017;265(3):604-8. https://doi.org/10.1097/SLA.0000000000001761.

9. Roland ME, Barin B, Huprikar S, et al. Survival in HIV-positive transplant recipients compared with transplant candidates and with HIV-negative controls. AIDS. 2016;30(3):435-44.

10. Muller E, Kahn D, Mendelson M. Renal transplantation between HIV-positive donors and recipients. N Engl J Med. 2010;362(24):2336-3233.

11. Organ procurement and transplantation. implementation of the HIV Organ Policy Equity Act. Final rule Fed Regist. 2015;80(89):26464-7.

12. Organ procurement and transplantation: implementation of the HIV Organ Policy Equity Act. Final rule, 80 FED REGIST. 2015. available at: https://advance-lexis-com.proxy1.library. jhu.edu/api/document?collection=administrative-codes\&id= urn:contentItem:5HFW-1RW0-006W-840M-00000-00\&conte $\mathrm{xt}=1516831$.
13. Rasmussen S, Glazier A, Cash A, Henderson M, Boyarsky B, Miller K, Schoettes S, Segev D, Durand C. State Law Restrictions on HIV Positive-to-Positive Transplantation. [meeting abstract]. Am J Transplant. 2017;17(suppl 3). https://atcmeeting abstracts.com/abstract/state-law-restrictions-on-hiv-positive-topositive-transplantation/.

14. Doby BL, Tobian AAR, Segev DL, et al. Moving from the HIV Organ Policy Equity Act to HIV Organ Policy Equity in action: changing practice and challenging stigma. Curr Opin Organ Transplant. 2018;23(2):271-8. https://doi.org/10.1097/MOT. 0000000000000510.

15. Boyarsky BJ, Bowring MG, Shaffer AA, et al. The future of HIV Organ Policy Equity Act is now: the state of HIV+ to HIV+ kidney transplantation in the United States. Curr Opin Organ Transplant. 2019;24(4):434-40.

16. Organ Procurement and Transplantation Network. HOPE Act. Transplant centers approved for HOPE Act. 2021. available at: https://optn.transplant.hrsa.gov/learn/professional-education/ hope-act/. Accessed July 28, 2021.

17. Organ Procurement and Transplantation Network. Adult Heart Allocation. available at: https://optn.transplant.hrsa.gov/learn/ professional-education/adult-heart-allocation/. Accessed July 28, 2021.

18. Redd AD, Quinn TC, Tobian AA. Frequency and implications of HIV superinfection. Lancet Infect Dis. 2013;13(7):622-8. https://doi.org/10.1016/S1473-3099(13)70066-5.

19. Boyarsky BJ, Durand CM, Palella FJ Jr, Segev DL. Challenges and clinical decision-making in HIV-to-HIV transplantation: insights from the HIV literature. Am J Transplant. 2015 Aug;15(8):2023-30. https://doi.org/10.1111/ajt.13344.

20. Stock PG, Barin B, Murphy B, et al. Outcomes of kidney transplantation in HIV-infected recipients. N Engl J Med. 2010;363(21):2004-14. https://doi.org/10.1056/nejmoa1001197.

21 Locke JE, Mehta S, Reed RD, MacLennan P, Massie A, Nellore A, Durand C, Segev DL. A national study of outcomes among HIV-infected kidney transplant recipients. J Am Soc Nephrol. 2015;26(9):2222-9. https://doi.org/10.1681/ASN.2014070726.

22. Terrault NA, Roland ME, Schiano T, et al. Outcomes of liver transplant recipients with hepatitis $\mathrm{C}$ and human immunodeficiency virus coinfection. Liver Transpl. 2012;18(6):716-26. https://doi.org/10.1002/lt.23411.

23. Locke JE, Durand C, Reed RD, et al. Long-term outcomes after liver transplantation among human immunodeficiency virusinfected recipients. Transplantation. 2016;100(1):141-6. https:// doi.org/10.1097/TP.0000000000000829.

24. Canaud G, Dejucq-Rainsford N, Avettand-Fenoël V, et al. The kidney as a reservoir for HIV-1 after renal transplantation. J Am Soc Nephrol. 2014;25(2):407-19. https://doi.org/10.1681/asn. 2013050564

25. Verna EC. Non-alcoholic fatty liver disease and non-alcoholic steatohepatitis in patients with HIV. Lancet Gastroenterol Hepatol. 2017;2(3):211-23. https://doi.org/10.1016/S2468-1253(16) 30120-0.

26. Durand CM, Zhang W, Brown DM, et al; the HOPE in Action Investigators. A prospective multicenter pilot study of HIV-positive deceased donor to HIV-positive recipient kidney transplantation: HOPE in action. Am J Transplant. 2020;00:1-11. https:// doi.org/10.1111/ajt.16205. (This prospective multicenter pilot study explores the safety of, and risks associated with, receiving an HIV+ organ, and demonstrates excellent overall transplant and HIV outcomes.)

27. Bonny TS, Kirby C, Martens C, et al. Outcomes of donor-derived superinfection screening in HIV-positive to HIV-positive kidney and liver transplantation: a multicentre, prospective, observational study. Lancet HIV. 2020;7(9):e611-9. https://doi.org/10. 1016/S2352-3018(20)30200-9. 
28. Selhorst P, Combrinck CE, Manning K, et al. Longer-term outcomes of HIV-positive-to-HIV-positive renal transplantation. N Engl J Med. 2019;381(14):1387-9.

29. Muller E, Barday Z, Mendelson M, Kahn D. HIV-positive-toHIV-positive kidney transplantation-results at 3 to 5 years. N Engl J Med. 2015;372:613-20.

30. Locke JE, James NT, Mannon RB, et al. Immunosuppression regimen and the risk of acute rejection in HIV-infected kidney transplant recipients. Transplantation. 2014;97(4):446-50.

31. Kucirka LM, Durand CM, Bae S, et al. Induction immunosuppression and clinical outcomes in kidney transplant recipients infected with human immunodeficiency virus. Am J Transplant. 2016;16(8):2368-76.

32. Calmy A, van Delden C, Giostra E, et al. HIV-positiveto-HIV-positive liver transplantation. Am J Transplant. 2016;16(8):2473-8. https://doi.org/10.1111/ajt.13824.

33. Lauterio A, Moioli MC, Di Sandro S, Travi G, De Carlis R, Merli M, Ferla F, Puoti M, De Carlis L. HIV-positive to HIVpositive liver transplantation: To be continued. J Hepatol. 2019;70(4):788-9. https://doi.org/10.1016/j.jhep.2018.06.026.

34. Hathorn E, Smit E, Elsharkawy AM, Bramhall SR, Bufton SA, Allan S, Mutimer D. HIV-positive-to-HIV-positive liver transplantation. N Engl J Med. 2016;375(18):1807-9. https://doi.org/10.1056/NEJMc1603850.

35. Centers for Disease Control and Prevention. Coronavirus disease 2019 people with certain medical conditions. 2021. Available at https://www.cdc.gov/coronavirus/2019-ncov/need-extra-precautions/ people-with-medical-conditions.html. Accessed June 15, 2021.

36.• Mehta SA, Rana MM, Motter JD, Small CB, Pereira MR, Stosor V, et al. Incidence and outcomes of COVID-19 in kidney and liver transplant recipients with HIV: report from the National HOPE in Action Consortium. Transplantation. 2021;105(1):216-24. https://doi.org/10.1097/tp.0000000000 003527. (This large prospective multicenter study noted high mortality from COVID-19 among HIV-positive kidney and liver transplant recipients.)

37. Boyarsky BJ, Hall EC, Singer AL, et al. Estimating the potential pool of HIV-infected deceased organ donors in the United States. Am J Transplant. 2011;11(6):1209-17. https://doi.org/10.1111/j. 1600-6143.2011.03506.x.

38. Richterman A, Sawinski D, Reese PP, et al. An assessment of HIV-infected patients dying in care for deceased organ donation in a United States urban center. Am J Transplant. 2015;15(8):2105-16.

39. Wilk AR, Hunter RA, McBride MA, Klassen DK. National landscape of HIV+ to HIV+ kidney and liver transplantation in the United States. Am J Transplant. 2019;19(9):2594-605. https:// doi.org/10.1111/ajt.15494.

40 Cain M, Mittman R. Diffusion of Innovation in Health Care. Oakland: California Healthcare Foundation; 2002.

41. Idaho Code Ann. § 39-608, available at https://advance-lexiscom.proxy 1.library.jhu.edu/api/document?collection=statu tes-legislation\&id=urn:contentItem:62PB-27W1-F1P7-B4KC00000-00\&context $=1516831$.

42. Kan. Stat. Ann. § 21-5424, available at https://advance-lexiscom. proxy1.library.jhu.edu/api/document? collection=statu tes-legislation\&id=urn:contentItem:5BY4-SR01-DYB8-317R00000-00\& context $=1516831$.

43. S.C. Code Ann. § 44-29-145 (This document is current through Act No. 30 of the 2021 Regular Session), available at: https:// advance-lexis-com.proxy1.library.jhu.edu/api/document?colle ction=statutes-legislation \&id=urn:contentItem:5K1J-NNH1DYB7-S1KV-00000-00\&context $=1516831$.

44. Cash A, Luo X, Chow EKH, Bowring MG, Shaffer AA, Doby B, Wickliffe CE, Alexander C, McRann D, Tobian AAR, Segev DL, Durand CM. HIV+ deceased donor referrals: A national survey of organ procurement organizations. Clif Transplant. 2018;32(2). https://doi.org/10.1111/ctr.13171.

45. HIV.gov. A Timeline of HIV/AIDS. Published 17 June 2021. https://www.hiv.gov/hiv-basics/overview/history/hiv-and-aidstimeline. Accessed: June 15, 2021.

46. Botha J, Fabian J, Etheredge H, et al. HIV and solid organ transplantation: where are we now. Curr HIV/AIDS Rep. 2019;16(5):404-13. https://doi.org/10.1007/s11904-019-00460-7.

47. Swanson SJ, Kirk AD, Ko CW, et al. Impact of HIV seropositivity on graft and patient survival after cadaveric renal transplantation in the United States in the pre highly active antiretroviral therapy (HAART) era: an historical cohort analysis of the United States Renal Data System. Transpl Infect Dis. 2002;4(3):144-7. https://doi.org/10.1034/j.1399-3062.2002.01009.x.

48 Spital A. Should all human immunodeficiency virus-infected patients with end-stage renal disease be excluded from transplantation? The views of U. S. transplant centers. Transplantation. 1998;65(9):118791. https://doi.org/10.1097/00007890-199805150-00008.

49. Halpern SD, Asch DA, Shaked A, et al. Determinants of transplant surgeons' willingness to provide organs to patients infected with HBV. HCV or HIV Am J Transplant. 2005;5(6):1319-25.

50. Sawinski D, Wyatt CM, Casagrande L, et al. Factors associated with failure to list HIV-positive kidney transplant candidates. Am J Transplant. 2009;9(6):1467-71. https://doi.org/10.1111/j. 1600-6143.2009.02637.x.

51. Boyle SM, Fehr K, Deering C, et al. Barriers to kidney transplant evaluation in HIV-positive patients with advanced kidney disease: a single-center study. Transpl Infect Dis. 2020;22(2):e13253. https://doi.org/10.1111/tid.13253.

52•• Predmore Z, Doby B, Bozzi DG, Durand C, Segev D, Sugarman J, Tobian AAR, Wu AW. Barriers experienced by organ procurement organizations in implementing the HOPE act and HIV-positive organ donation. AIDS Care. 2021;28:1-7. https://doi.org/10. 1080/09540121.2021.1945999. (This study identified several OPO-level barriers to HIV-positive organ recovery, including obtaining authorization for donation, possibility of disclosing HIV status to next-of-kin, and fear of HIV infection.)

53. Van Pilsum Rasmussen SE, Seaman S, Johnson MA et al Patients' experiences with HIV-positive to HIV-positive organ transplantation. Transplantation Direct. In press.

54. Madhusoodanan J. Inner Workings: Advances in infectious disease treatment promise to expand the pool of donor organs. Proc Natl Acad Sci. 2021;118(8):e2100577118. https://doi.org/ 10.1073/pnas.2100577118.

55. Seaman SM, Van Pilsum Rasmussen SE, Nguyen AQ, et al. Brief report: willingness to accept $\mathrm{HIV}$-infected and increased infectious risk donor organs among transplant candidates living with HIV. J Acquir Immune Defic Syndr. 2020;85(1):88-92. https:// doi.org/10.1097/QAI.0000000000002405.

56. Nambiar PH, Doby B, Tobian AR, Segev DL, Durand CM. Increasing the donor pool: organ transplantation from donors with HIV to recipients with HIV. Annu Rev Med. 2021;72(1):107-18. https://doi.org/10.1146/annurev-med-060419-122327.

57. Nguyen AQ, Anjum SK, Halpern SE, et al. Willingness to donate organs among people living with HIV. J Acquir Immune Defic Syndr. 2018;79(1):e30-6. https://doi.org/10.1097/QAI.0000000000001760.

58. Bhamidipati D, Veldkamp P, Despines L, et al. A pilot study of organ donor registration among persons living with HIV (PLWH) [abstract]. Am J Transplant. 2019; 19 (suppl 3). https://atcmeeting abstracts.com/abstract/a-pilot-study-of-organ-donor-registrationamong-persons-living-with-hiv-plwh/. Accessed June 22, 2021.

Publisher's Note Springer Nature remains neutral with regard to jurisdictional claims in published maps and institutional affiliations. 